\title{
Alternation of generations in Andricus corruptrix (Schlechtendal): comments on and description of a new sexual form (Hymenoptera: Cynipidae)
}

\author{
R. Folliot ${ }^{1}$, P. Ros-Farré ${ }^{2}$, D. Bellido ${ }^{2} \&$ J. Pujade-Villar ${ }^{2}$ \\ ${ }^{1}$ Université de Rennes 1, Faculté Sciences, C.N.R.S. UPRES-A 6026, Equipe Canaux Récepteurs \\ Membranaires, Bât 13-Campus de Beaulieu, 35042-Rennes Cedex-France; ${ }^{2}$ Universitat de Barcelona \\ Facultat de Biologia, Departament de Biologia Animal, Avda Diagonal 645, E-08028-Barcelona
}

Keywords: Hymenoptera, Cynipidae, Andricus, A. corruptrix, A. improprius, life cycle, new form

\begin{abstract}
Life cycle of $A$. corruptrix (Schlechtendal, 1870) is treated and corrections to previous experiments are discussed. A new sexual form for $A$. corruptrix is herein described, while $A$ corruptrix forma larshemi is considered a valid species and for taxonomical reasons is renamed as Andricus improprius n. stat \& n.sp, only known by the sexual form, and not linked with $A$. corruptrix. Lectotypes for $A$. improprius n. stat \& n. sp. (= A. larshemi not available) are also designated.
\end{abstract}

\section{Contents}

Introduction

Material and methods

Results

The bisexual form of Andricus corruptrix (Schlechtendal)

Andricus corruptrix (Trotter) new bisexual form

Taxonomic comments on Andricus corruptrix $\mathrm{f}$. larshemi D. van L. \& D.-M., 1958

Andricus improprius Bellido \& Pujade-Villar n. stat. \& n. sp

Discussion

Acknowledgements

References

\section{Introduction}

In most oak gallwasps the reproduction is an example of cyclical parthenogenesis or heterogony. The lifecycle involves alternation of a bisexual generation and a partenogenetic (unisexual or asexual) generation. The two generation are strictly alternating. The cycle is commonly completed within a single year. In some species the two generations ate morphologically different and develop in galls of different types on different parts of the host plant. The link between the unisexual and bisexual generations of one species can be revealed by carefully controlled rearing experiments. In the large genus Andricus for instance, in Europe, the two generations of many species are known (PujadeVillar et al., 2001) but many other species are known only by their unisexual generation and a few other by their bisexual generation only. Modern molecular biology methods, for example DNA sequencing, can help to suspect a specific link between two previously unlinked bisexual and unisexual forms. Rearing experiments remain the necessary method to determine the two alternating generations of a species.

In most species the galls of the two alternating generations develop on the same oak species. In the case of Andricus kollari the gall of the unisexual generation develops on Quercus robur, $Q$. petraea and $Q$. pubescens. First studies of alternation of generations in the Andricus kollari group were made by Beijerinck (1902), who found that Andricus circulans, a sexual form galling another oak species, Quercus cerris, was the sexual generation of Andricus kollari. Such a situation is called heteroecism. These experiments were considered as doubtful by many hymenopterologists of his time, until Marsden-Jones (1953) and Folliot (1964) confirmed their results.

The genus Andricus contains several groups of neighbouring oak gallwasps (Stone \& Cook, 1998). One of them, called the kollari group (Bellido et 
al., 2003), contains the species listed in table 1 . Docters van Leeuwen (1956) and Docters van Leeuwen \& Dekhuijzen-Maasland (1958) studied the lifecycle of two other species of this group, Andricus lignicolus and Andricus corruptrix. They collected galls of the unisexual form of these two species on $Q$. robur and they described, also on $Q$. cerris, the sexual form of $A$. corruptrix and $A$. lignicolus, respectively named 'larshemi' and 'vanheurni'. Wiebes-Rijks (1978) gave diagnostic characters to separate the three known sexual forms ( $A$. kollari, A. lignicolus and $A$. corruptrix). These three species, now widespread in a great part of Europe, are not native in The Netherlands and were introduced together with one of their hosts, $Q$. cerris. This introduction enabled species of the $A$. kollari group, once restricted to Eastern Europe, to colonize new zones (Quinlan, 1974; Askew \& Neill, 1993).

After Beijerinck and Docters van Leeuwen, the status of the above three heterogonic species was thought to be the following:

Unisexual form

A. kollari (Hartig, 1843)

A. lignicolus (Hartig, 1840)

A. corruptrix (Schlechtendal, 1870)
Sexual form circulans Mayr, 1870

vanheurni D. van L. \&

D.-M., 1958

larshemi D. van L. \& D.-M., 1958 [not available]
One of us (R. F.) found in Rennes (Brittany, France) similar unisexual galls to those named $A$. corruptrix in Docters van Leeuwen pictures. Experiments with the unisexual adults were undertaken in order to obtain sexual generation and to compare it with the sexual generation obtained by Docters van Leeuwen and other known sexual generations of species of the kollari group.

\section{Material and methods}

At first, it was observed, in a glass jar that $A$. corruptrix females could lay eggs in $Q$. cerris buds (one egg was found after dissection in the heart of a bud).

Different experiments were made, three of them on $Q$. cerris with one unisexual female each. In one experiment the oak branch died too early after six months. In another nothing was obtained. The third experiment was successful and is described hereunder in more details.

One female of $A$. corruptrix reared in Rennes on the $25^{\text {th }}$ of June, 1997 was taken to Puilboreau (Baillac), near to La Rochelle, a more southern place in France where, despite intense monitoring, $A$. corruptrix has never been found. There, on the $27^{\text {th }}$ of June, 1997, it was placed inside a sleeve on Quercus cerris.

Table 1. Alternation of generations in A. kollari group

\begin{tabular}{|c|c|c|c|}
\hline Unisexual form & Sexual form & Sexual form host tree & Author closing cycle \\
\hline A. kollari & A. circulans' & Q. cerris & Beijerinck (1902) \\
\hline A. hispanica & & Q. suber & Pujade-villar (unpl. data) \\
\hline A. lignicolus & A. vanheurni $i^{3}$ & Q. cerris & D.v.L \& D-M (1958) \\
\hline A. corruptrix $\left(=A\right.$. ambiguus $\left.{ }^{2}\right)$ & & Q. cerris & Present paper \\
\hline A. infectorius & Unknown $^{4}$ & Q. cerris? & - \\
\hline A. amblycerus & Unknown & Q. cerris? & $\longrightarrow$ \\
\hline A. aries & Unknown & Q. cerris? & $\longrightarrow$ \\
\hline A. caliciformis & Unknown & Q. cerris? & - \\
\hline Unknown & A. improprius ${ }^{5}$ & Q. cerris & $\longrightarrow$ \\
\hline
\end{tabular}

(1) According to Pujade-Villar, 1992 and Pujade-Villar et al. 2001; known but not described; before mentioned as $A$. kollari in the Iberian Peninsula.

(2) Non valid species according Bellido, Melika \& Pujade-Villar (submitted).

(3) The new sexual, in this paper, do not have a specific name, following the article 15 of the International Code of Zoological Nomenclature.

(4) A. burgundus has been recorded as the sexual generation of A. infectorius (=tinctoriusnostrus, according to Melika et al, 2000), but recent papers argue against that (Stone \& Cook, 1998; Cook et al, 1999).

${ }^{\text {(5) }}$ n. stat and n. sp. to Andricus corruptrix forma larshemi (in this paper). 
The sleeve was left from $27^{\text {th }}$ June, 1997 until $20^{\text {th }}$ April, 1998, to avoid oviposition by $A$. kollari and $A$. lignicolus (although this last species is very rare in the zone) and later, predation by birds, which frequently attack growing galls in the oak buds. We obtained galls and insects of the sexual generation which will be treated further in more details.

Our specimens were compared with both unisexual and sexual material obtained by Docters van Leeuwen and Dekhuijzen-Maasland in their experiments, deposited in Zoölogisch Museum Amsterdam (Netherlands). Unfortunately, only 4 unisexual females of Andricus corruptrix and 2 sexual females of $A$. larshemi are left of the material used in the experiments of Docters van Leeuwen. Our specimens were also compared with material of the unisexual and sexual froms of $A$. lignicolus and $A$. kollari, experimentally obtained by Roger Folliot. Unfortunately no types of $A$. vanheurni were found among the Docters van Leeuwen material collections. Only 3 unisexual females of $A$. lignicolus used in the experiments were left (Hogenes, pers. com.).

SEM pictures were made by the second author. The pictures were made at low voltage and without coating to preserve specimens from damage.

We follow the current terminology of morphological structures as given in Gibson (1985), Ronquist and Nordlander (1989), and Fergusson (1995). Abbreviations for fore wing venation follow Ronquist and Nordlander (1989). The measurements and abbreviations used herein include: F1 F12, 1st and subsequent flagellomeres; POD (postocellar distance), the distance between the inner margins of the posterior ocelli; OOD (oculo-ocellar distance) for distance between inner margin of eye and lateral ocelli; COD (central-ocellar distance) for distance between lateral and central ocelli.

\section{Results}

In April, 1998, 8 isolated galls were found inside the sleeve, from which we reared 5 alive females, 2 males and one dead parasitoid. This parasitoid is not a cynipid parasitoid, and may come from the branch used in the. experiment. One gall remained closed.
The bisexual form of Andricus corruptrix (Schlechtendal)

Sexual adults obtained from the experiment were compared with $A$. larshemi types from Docters van Leeuwen collection, sexual adults of $A$. kollari $(=c i r-$ culans) and $A$. lignicolus (=vanheurni) experimentally obtained by Folliot and descriptions present in the literature (Wiebes-Rijks, 1978). They are clearly different from all these forms.

We compared also unisexual females used by Docters van Leeuwen in his experiments with our $A$. corruptrix female and we found they belonged to the same species. As the unisexual females appear to be identical and the obtained sexual forms different, one of the two experiments must have been contaminated by another species. Docters van Leeuwen \& Dekhuijzen-Maasland were successful in their attempt to produce unisexual form galls from șexual insects but in other experiments, they obtained sexual galls under arguable conditions since nets were kept on the host for only two weeks (Docters van Leeuwen \& Dekhuijzen-Maasland, 1958). In our opinion the contaminant could not be $A$. lignicolus or $A$. kollari since their sexual generations are different, but an undetected species of the $A$. kollari group which has been confused with other species. Consequently, the name $A$. larshem $i$ points to a valid species the unisexual generation of which is unknown.

To sum up, the sexual form of $A$. corruptrix is not the form larshemi described by Docters van Leeuwen but a new form, which we describe hereunder.

\section{Andricus corruptrix (Trotter) new bisexual form}

Studied material: Experimental material, 2 males and 5 females of the previously described experiment (VI-1997/ IV-1998); 2 males and 2 females; material deposited in Barcelona University; 2 females (also paratypes) deposited in MNHN (Paris).

Length: $1.6-1.8 \mathrm{~mm}$ (for males) and 1.8-2 $\mathrm{mm}$ (for females).

Colour: All the body black. Wing veins dark brown. Female head (Figs. 1a \& 1b). Without pubescence; in dorsal view around 2.5 times wider than long. Genae coriaceous, not broadened behind compound 

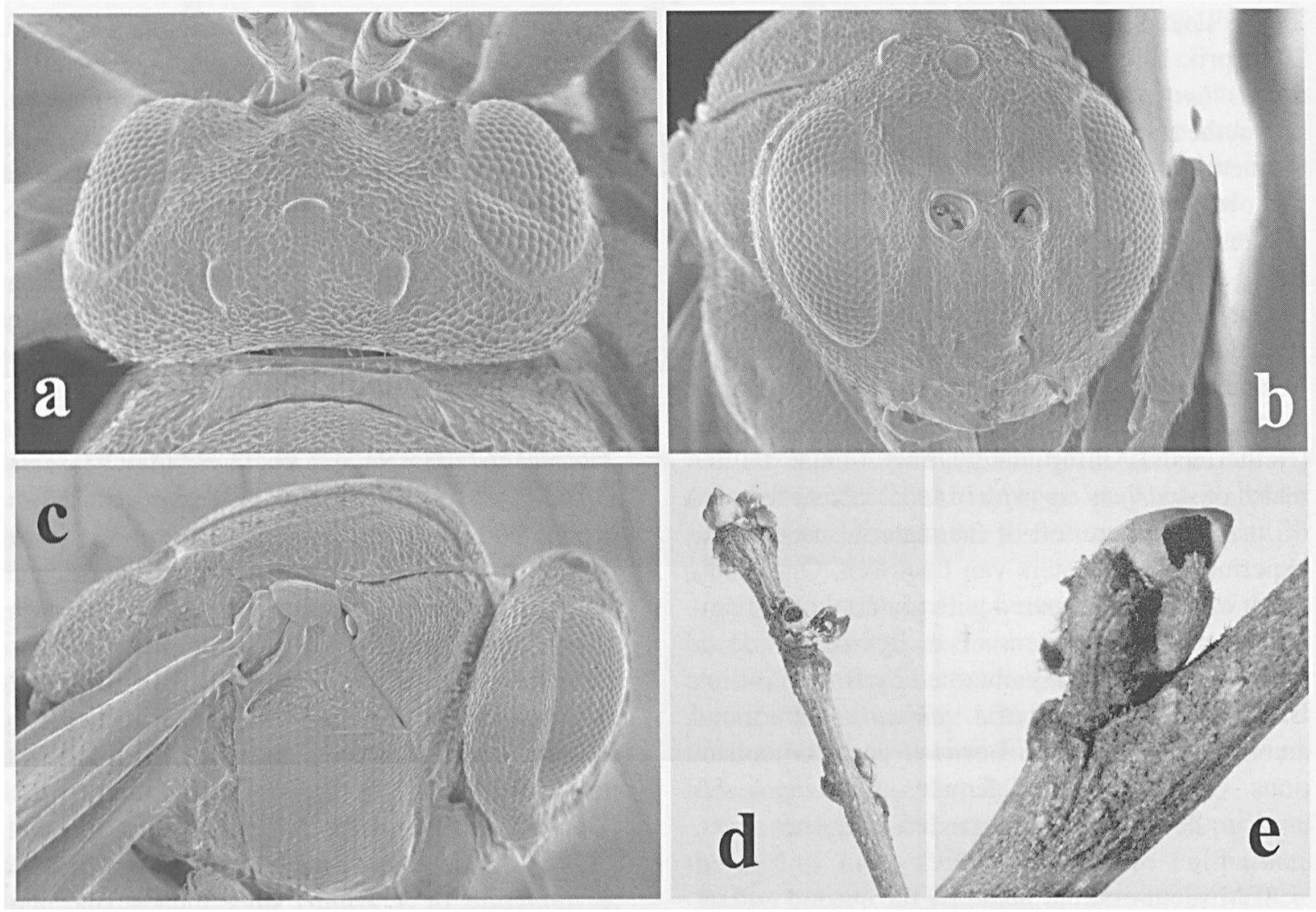

Fig. 1. A. corruptrix bisexual form: a) head of in dorsal view; b) head in frontal view; c) lateral view; d) branch with some galls; e) isolated gall.

eyes. POD twice OOD; OOD 1.5 times lateral ocellus diameter and more or less equal to COD (ratio POD:OOD:COD:lateral ocellus diameter is 45:23:23:15). Coriaceous sculpture. Clypeus conspicuous and suboval in shape. Face with only some very short and weak irradiating striae around clypeus, never reaching neither antennal toruli nor compound eye margin. Transfacial line more or less equal to eye height. Diameter of toruli around twice the distance between them and slightly larger than distance between toruli and eye margin. Male head similar to female.

Female antenna (fig. 2a) with 13 segments, 0.8 times body length or slightly longer; pedicel 2 times longer than wide; F1 is 1.2 times longer than F2 and 1.6 times pedicel length; following flagellomeres gradually decreasing in length, last flagellomeres conspicuously longer than wide and last more or less twice its width. Male antenna (fig. 2b) with 14

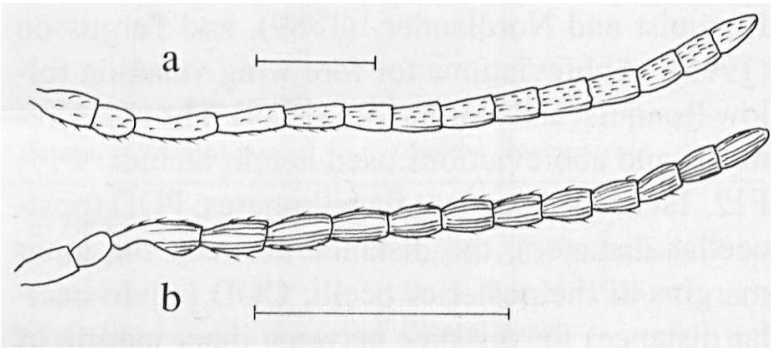

Fig. 2. Antenna of A. corruptrix bisexual form: a) female (scale bar 200 micrometres); b) male (scale bar 500 micrometres)

segments, the third one curved, dorsally flattened, proximally excavate and distally expanded; number of sensilla in each segments higher (6-8) than in females.

Female mesosoma (figs. 3b, 3d, 3f). Without pubescence except for some hairy zones in the propodeum, with coriaceous sculpture. Notauli com- 

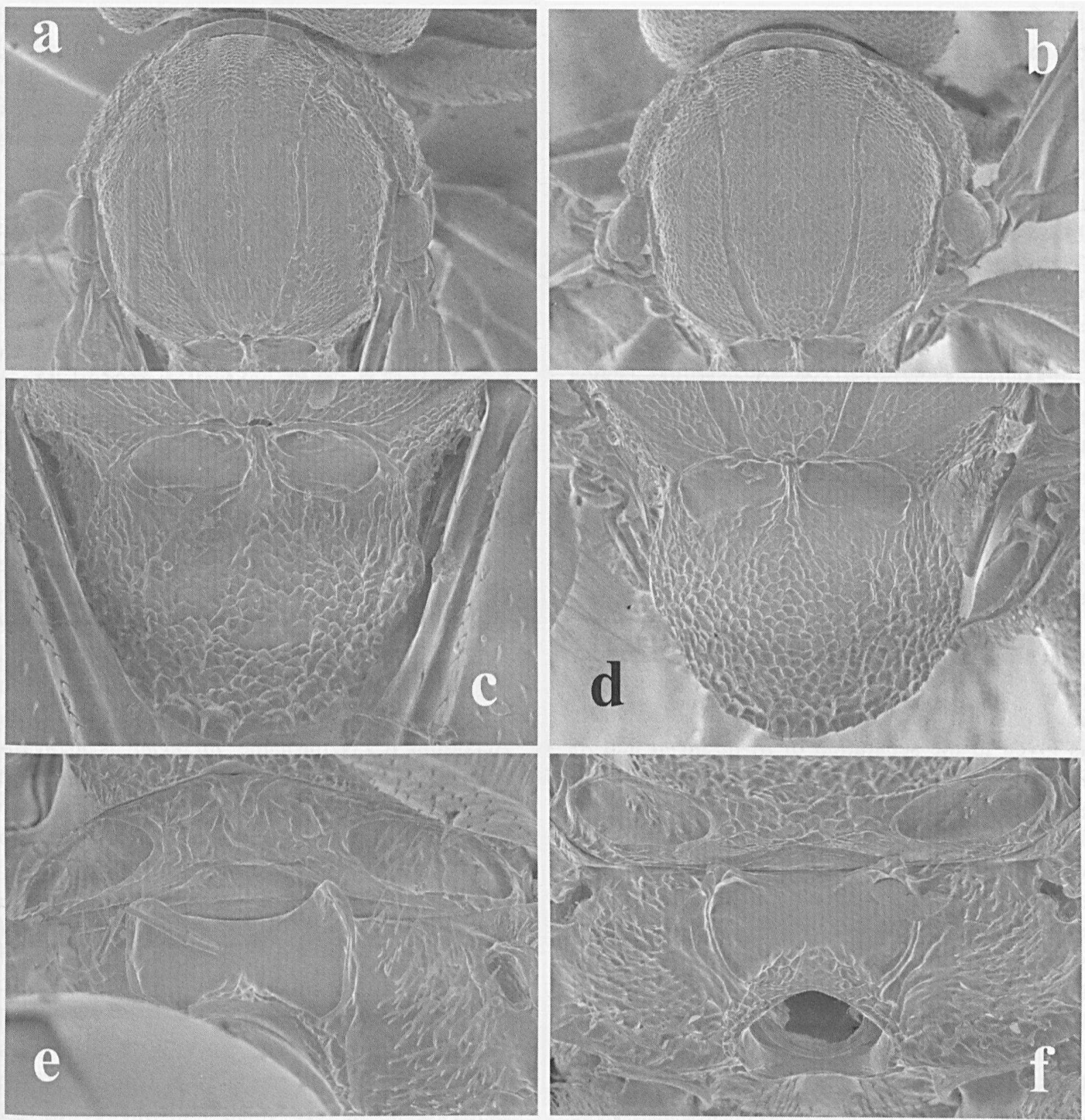

Fig 3. Scutum in dorsal view (a, b), scutellum in dorsal view (c, d) and propodeum (e,f) of the bisexual form of Andricus improprius new status \& n. sp. (a, c, e) and $A$. corruptrix new form (b, d, f)

plete and deep in all its length, always reaching pronotal margin, converging posteriorly and widening (posterior notauli width at least one third of distance between them), delimiting an area with regular closely reticulate sculpture (not longitudinally striated) (Fig. 3b). Median mesoscutal im* pression absent. Mesopleuron (Fig. 1c) almost com- pletely striated with some striation also in pronotum. Scutellum subquadrate, only slightly wider than long, with closely reticulated sculpture, not marginated laterally and not lobed posteriorly. Scutellar foveae (Fig. 3d) oval, with a transversal disposition, smooth, shiny and not pubescent inside, not delimited posteriorly by a carina and separated from each other by 
a median carina. Lateral carinae of propodeum (Fig. 3f) thin, of an uniform thickness, bowed outwards, internal area shiny and smooth, not closed in its superior part (a carina close to the superior part of propodeal area in $A$. larshemi). Wings hyaline. Forewing margin with short and scattered setae in its anterior margin; radial cell 4-4.5 times longer than broad; $2 \mathrm{r}$ vein angled; areolet usually conspicuous. Tarsal claws of legs with an acute basal lobe and forming a close angle; anterior tibiae provided with short and applied hairs. Male mesósoma similar to female.

Female metasoma. Slightly shorter than head plus mesosoma together; without pubescence except at the basis of the $3^{\text {rd }}$ abdominal tergite. Third abdominal tergite covering between $1 / 2$ and $3 / 4$ of metasoma in dorsal vision. Ventral spine of hypopigium slightly longer than broad, with sparse setae, which do not form an apical tuft. Male metasoma smaller than mesosoma.

Diagnosis. It can be easily separated from other sexual forms of the A. kollari group by the following combinations of characters (special emphasis is given to the separation of $A$. larshemi and $A$. corruptrix bisexual form because they are the most similar forms). Upper part of propodeum not closed by a complete carina, while in $A$. larshemi it is conspicuously closed (figs. $3 \mathrm{e} \& 3 \mathrm{f}$ ), mesoscutal sculpture between notauli regularly reticulated, not elongated like in A. larshemi (figs. $3 c$ \& 3d) and scutellar foveae not delimited posteriorly while they are delimited in A. larshemi (figs. 3c \& 3d), sculpture between notauli regularly reticulated (like in A. circulans) but never elongated like in $A$. larshemi (figs. 3a \& 3b), scutellar sculpture weaker than in A. lignicolus (= vanheurni) or A. kollari (= circulans), and regularly reticulated and not coarse.

Distribution. Only known in experimental conditions from France, where the unisexual form has probably been introduced recently.

Gall. Similar to other sexual galls of the A. kollari group. A small bud gall. (fig. ld), measuring between 2 and $2.5 \mathrm{~mm}$ from basis to top, on Q. cerris, isolated (unlike those of $A$. circulans or A. larshemi), with its basal part hidden from view by bud-scales and apical part projected outside. The surface of the gall is brown, nearly smooth, without striation, and with a short and deciduous pubescence. The tops are pointed, not rounded, and the gall wall is very thin. Adults leave the gall through a circular, big and lateral opening below the top.

Taxonomic comments on Andricus corruptrix $\mathrm{f}$. larshemi D. van L. \& D.-M., 1958

The insects named "larshemi" by Docters van Leeuwen \& Dekhuijzen-Maaland (1958) do not represent the sexual form of $A$. corruptrix but correspond to another valid species only known by its sexual form. Consequently, what is the status of the name "larshemi"?.

As evidences in this study show the life cycle of Andricus corruptrix was erroneously described by Docters van Leeuwen (1956: 255). The sexual form was given the name $A$. corruptrix forma larshemi in Docters van Leeuwen \& Dekhuijzen-Maasland (1958: 102, 104) and not in Docters van Leeuwen (1956) as it's stated in Wiebes-Rijks (1978: 140). According ICZN, the name "larshemi" is not available for two reasons: because it's described as a form of a previous species (art. 45.6.1) and because it's described from galls and not adults (arts.1.3.6 i 13.1.1).

Actually, Docters van Leeuwen \& DekhuijzenMaasland (1958: 102) stated that sexual adults of "larshemi" form are indistinguishable from bisexual adults of Andricus kollari. Moreover Eady \& Quinlan (1963: 49) gave differences between sexual females of "larshemi" and "circulans", since males were unknown to them (Eady \& Quinlan, 1963: 52). These authors never explicitly mentioned that "larshemi" belong to a taxonomical category other than 'form', and thus the name continues as not available. Later, Wiebes-Rijks (1978) gave diagnostic characters for both sexes of "larshemi" but continued considering them as a form of $A$. corruptrix, and thus the name can't be used according ICZN (art. 15.2, 45.6.1 i 46.6.3).

First author giving "larshemi" a different taxonomic status (A. corruptrix ssp larshemi) was Ambrus (1974:26), but his name can't be used either, because he only described galls, and according ICZN 
again, infra specifics terms can't be used after 1960 (art. 15.2) and gall descriptions are not considered valid for taxonomic purposes after 1930 (art. 1.3.6). Therefore "larshemi" remains not available after Ambrus' paper.

Finally, Melika et al. (2000: 269) consider "larshemi" as a different species from data shown in this study, but it's not characterised morphologically, and thus "larshemi" can't be available either (art. 1.3.6).

At last we consider the previously named form "larshemi", neither linked to Andricus corruptrix nor to Andricus kollari and Andricus lignicolus as a valid species only known by its sexual form but for taxonomic reasons we rename this species as Andricus impropius n. stat. \& n. sp.

Andricus improprius Bellido \& Pujade-Villarn. stat. \& n. sp.

Andricus corruptrix forma larshemi Docters van Leeuwen \& Dekhuijzen-Maasland (1958) [not available]

Andricus corruptrix (=larshemi) Eady \& Quinlan (1963) [not available]

Andricus corruptrix forma larshemi Wiebes-Rijks (1978) [not available]

Andricus corruptrix ssp larshemi Ambrus (1974) [not available]

Andricus larshemi Melika, Csóka \& Pujade-Villar (2000) [not available]

Studied material (deposited in Zoölogisch Museum Amsterdam). Lectotype $Q$ herein designated with following labels: "Andricus corruptrix Schlechtendal forma larshemi ơ $\$$ D. v. L. et J. M.D.-M. Leersum, 10.v.1955" (handwriting); "Lectotype" (red label); "Andricus improprius, Bellido \& Pujade-Villar det. 2000" (white label). Paralectotype $\$$ with the same labels except for a "Paralectotype" label (red).

Diagnostic characters for adults of $A$. improprius are given in Wiebes-Rijks (1978) and in this study (fig. 3a, c, e), galls are described in Docters van Leeuwen \& Dekhuijzen-Maasland (1958).

\section{Discussion}

The time of sleeve enclosure in our experiment was long: almost ten months from June to following April. The enclosure was, at first, intended to prevent contamination by $A$. kollari and $A$. lignicolus." This last species can emerge as early as May in
Brittany but is very rare in Baillac (France) where since several decades it has been found only once. $A$. kollari, in Baillac emerges (in the $2^{\text {nd }}$ year) usually from July. At any rate, the sexual adults obtained do not belong neither to $A$. lignicolus (=vanheurni) nor to $A$. kollari (=circulans), as we have discussed above.

The presence of both sexes originating from one unisexual female may seem strange as the norm in Andricus is usually to find sexual adults originating from one unisexual female of only one sex (all males or all females). But in the allied species $A$. kollari, Folliot (1964: 493) observed a similar situation in several instances, usually one or a few sexual females in the progeny of a male producing unisexual female and eventually when small numbers are concerned, more females than males. At any rate both sexes described here are morphologically similar and different from the other three known sexual forms in the group. Therefore we consider the new sexual form as the valid form alternant with Andricus" corruptrix (Trotter).

To sum up, all the known life-cycles of the species of $A$. kollari group are presented in table 1 . Sexual generation of other species of the group may have $Q$. cerris as host as most known species but, the host tree of these sexual generations is still unknown and therefor here indicated with a question mark.

\section{Acknowledgements}

We thank Willem Hogenes (Zoölogisch Museum Amsterdam, Netherlands) for loaning material and for his help in search of Docters van Leeuwen experimental material, and Dr. Karla Schneider (Institut fuer Zoologie der Marthin-Luther-Universitaet, Halle, Germany) for loan of type material of $A$. corruptrix. Finally we remain grateful to Dr. M.A. Alonso Zarazaga (Museo de Ciencias Naturales, Madrid, Spain) for comments concerning ICZN, to Dr. G. Melika (Systematic Parasitoid Lab, Hungary) for additional material of $A$. corruptrix and A. ambigutis for comparison and to our friend Albert Masó for pictures of Andricus corruptrix galls in this paper.

\section{References}

Ambrus B. 1974. Cynipida-Gubacsok-Cecidia Cynipidarum. Magyarország állatvilága (Fauna Hungariae), XII, 2. Akadémiai Kiadó, Budapest. 120 pp

Askew RR, Neill MP. 1993. Parasitoids and inquilines of 
the unisexual generation of Andricus lignicola (Hymenoptera: Cynipidae) in Britain. The Entomologist, 112: 4348.

Bellido D, Ros-Farré P, Melika G, Pujade-Villar J. 2003. Review of the asexual forms of Andricus kollari speciesgroup (Hymenoptera: Cynipidae: Cynipinae: Cynipini). Folia Entomol. Hungar., 64: 171-222.

Bellido D, Melika G, Pujade-Villar J. (submitted). Taxonomic spatus of Andricus corruptrix, A. amblycerus and A. ambiguus (Hym., Cynipidae). Deutsche Entomologische Zeitschrift

Beijerinck MW, 1902. Ueber die sexuelle Generation von Cynips kollari. Marcellia, 1: 13-18.

Cook JM, Stone GN, Rowe A. 1999. Patterns in the evolution of gall structure and life cycles in oak gall wasps (Hymenoptera: Cynipidae). The Biology of Gall-Inducing Arthropods. pp. 261-279. North Ctral. Res. Station. Forest Service, U.S. Dept. of Agric. Minnesota.

Dalla Torre CW, Kieffer JJ. 1910. Cynipidae. Das Tierreich, 24. Berlin: $891 \mathrm{pp} .+35 \mathrm{pl}$.

Docters van Leeuwen WM. 1956. The bigamic generations of Andricus corruptrix Schlechtendal and Andricus lignicolus Hartig (Hymenoptera, Cynipidae). Tijdschr. Ent., 98: 251-256.

Docters van Leeuwen WM, Dekhuijzen-Maasland JM. 1958. The bigamic generations of Andricus corruptrix Schlechtendal and Andricus lignicolus Hartig (Hymenoptera, Cynipidae). Part II. Tijdschr. Ent., 101: 101-111.

Eady RD, Quinlan J. 1963. Hymenoptera. Cynipoidea. Handbooks for the identification of British insects. Royal Entomol. Soc. of London. Vol. 8, Part I(a). 81 pp.

Fergusson NDM. 1995. The cynipoid families. pp. 247-265. In: Hanson, P. E. and I. D. Gauld, (eds.). The Hymenoptera of Costa Rica. Oxford, New York, Tokyo, Oxford University Press, 893 pp.

Folliot R. 1964. Contribution à l'étude de la Biologie des Cynipides gallicoles (Hyménoptères, Cynipoidea). Ann. Sci. Naturelles, Zool., 12e serie, t. VI: 407-564. 5 pl.

Gibson GAP. 1985. Some pro- and mesothoracic structures important for phylogenetic analysis of Hymenoptera, with a review of terms used for the structures. Canadian, Entomologist, 117: 1395-1443.

Horn W, Kahle I, Friese G, Gaedike R. 1990. Collectiones entomologicae. Akademie der Landwirtschaftswissenchaften der Deutschen Demokratischen Republik. Teil II: L bis Z: 223-540.

Houard C. 1908. Les Zoocécidies des Plantes d'Europe et du Bassin de la Mediterranée, Vol. I. Mus. Hist. Nat. Labor. Entom., Paris: 1-569

Ionescu MA. 1957. Cynipinae. Fauna Republicii Populare Romîne, 9 (2): 1-246. Ed. Acad. Republicii Popul. Rom. (In Romanian).

Kieffer JJ. 1897-1901. Monographie des Cynipides d'Europe et d'Algerie. Ibalynae et Cynipinae. Paris. Lib. Scient. A. Hermann. 689 pp. 27 pl.

Marsden-Jones EM. 1953. A study of the life-cycle of Adleria kollari Hartig, the marble or Devonshire gall. Trans. $R$. ent. Soc. London., 104: 195-221.

Melika G, Csóka Gy, Pujade-Villar J. 2000. Check-list of oak gall wasps of Hungary, with some taxonomic notes (Hymenoptera: Cynipidae, Cynipinae, Cynipini). Annls. hist.-nat. Mus. natn. hung., 92: 265-296.

Pujade-Villar J. 1992. Andricus kollari (Hartig) (Insecta: Hymenoptera: Cynipidae) Part II: Consideracions sobre el seu cicle biológic. La Sitja del Llop, 3:12.

Pujade-Villar J, Bellido DG, Segú G, Melika G. 2001. Current state of knowledge of heterogony in Cynipidae (Hymenoptera, Cynipoidea). Ses. Entom., ICHN-SCL, 11 (1999): 85-105.

Ronquist F, Nordlander G. 1989. Skeletal morphology of an archaic cynipoid, Ibalia rufipes (Hymenoptera: Ibaliidae). Entomologica Scandinavica, Suppl., 33: 1-60.

Quinlan J. 1974. On the occurrence of Andricus lignicola (Hartig) (Hym., Cynipidae) in Britain. Entomologist's Gazette, 25: 293-296.

Stone GN, Cook JM. 1998. The structure of Cynipid oak galls: patterns in the evolution of an extended phenotype. Proc. R. Soc. Lond. B, 265: 979-988.

Tavares JS. 1931. Os Cynipides da Peninsula Ibérica. Brotéria. Ser. Zool., 26: 5-100.

Trotter A. 1899. Contributo alla conoscenza degli entomocecidi italiani con la descrizione di due specie nuove di Andricus. Riv. patol. veg.,. 7: 281-311.

Wiebes-Rijks AA. 1978. The sexual generation of the Andricus kollari-group in The Netherlands (Hymenoptera, Cynipidae). Entomologische Berichten, 38: 139-142.

Received: 20 January 2003

Accepted: 31 March 2004 